Centimeter

Association for Information and Image Management

1100 Wayne Avenue. Suite 1100

Silver Spring Maryland 20910

$301 / 587.8202$

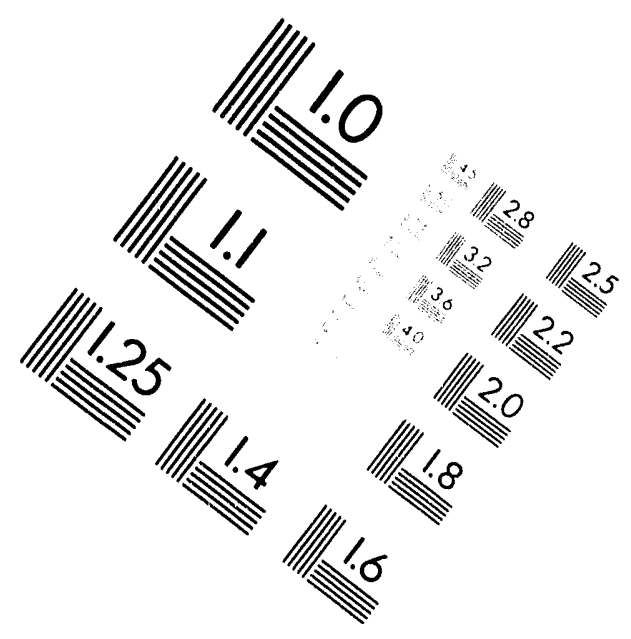

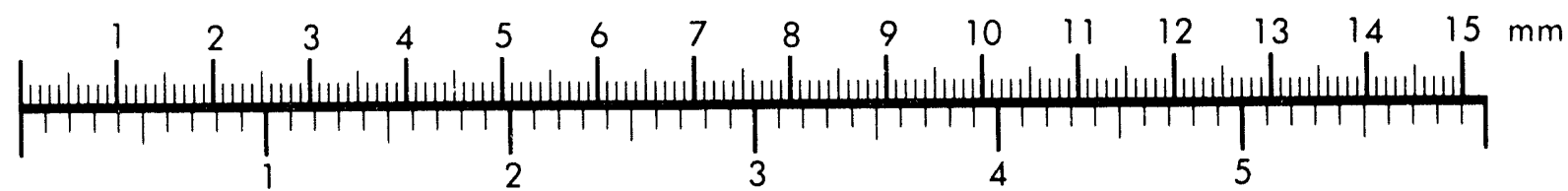

Inches
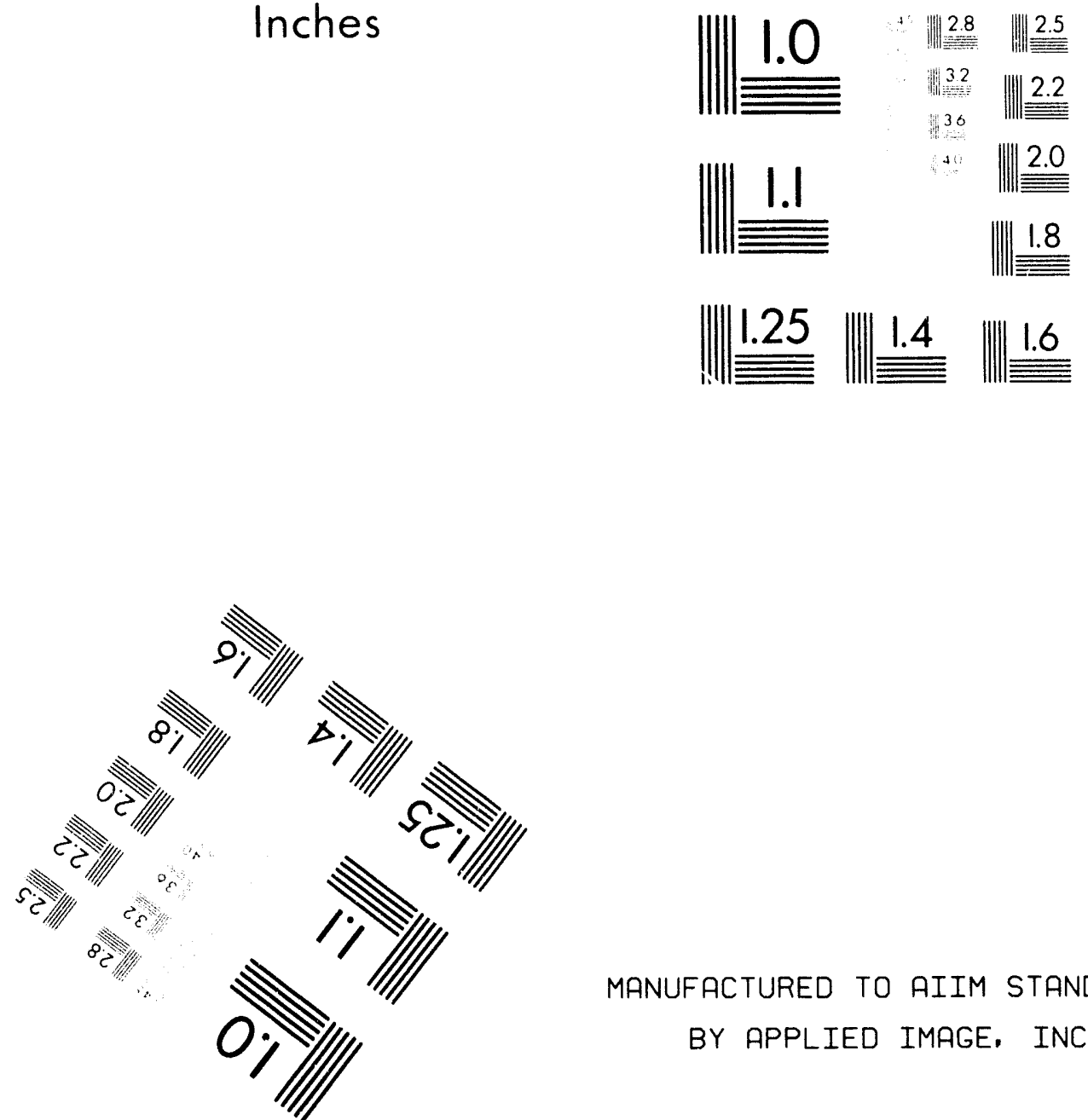

MANUFACTURED TO AIIM STANDARDS

BY APPLIED IMAGE, INC.

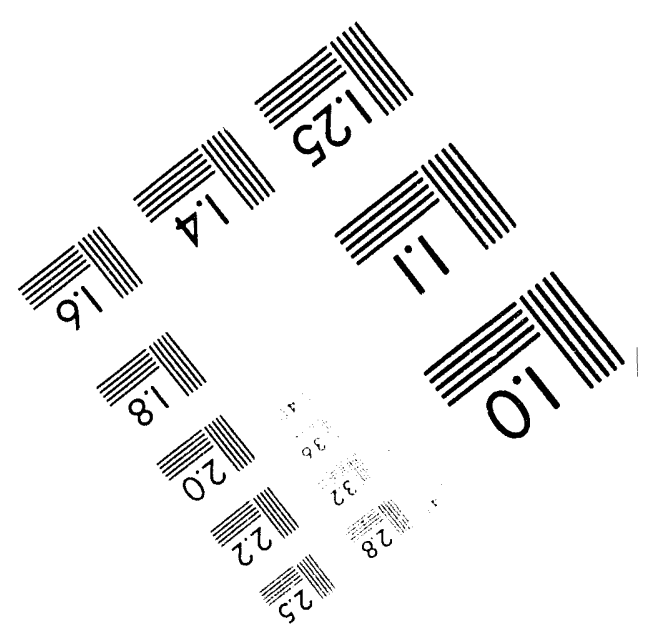



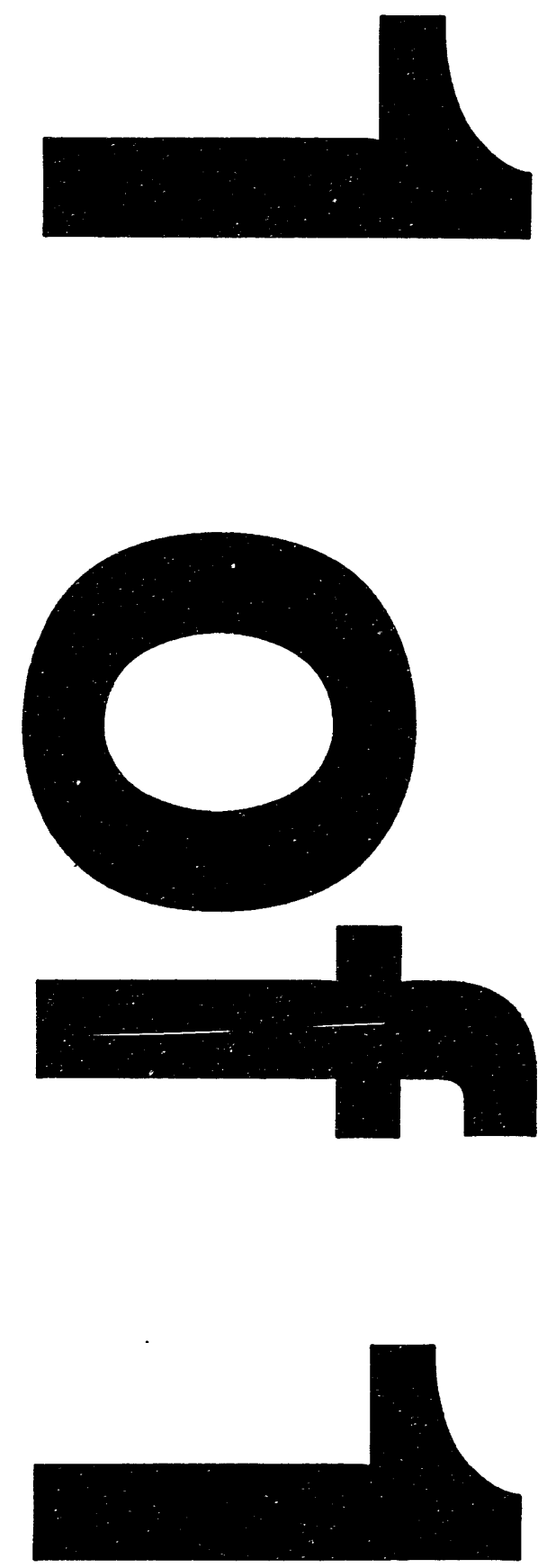


\title{
PHOTOCHEMISTRY WITHOUT PHOTONS. RADICAL CATION CHEMISTRY IN ZEOLITES
}

\author{
A. D. Trifunac and M. V. Barnabas \\ Chemistry Division, Argonne National Laboratory
}

Photochemical transformations of radical cations can be realized in zeolites without photons. A comprehensive study, supported by the Division of Chemical Sciences, Office of Basic Energy Sciences, of norbornadiene (NBD) and quadricyclane (Q) in ZSM-5 zeolites has revealed a multitude of radical cation reactions and pathways never seen before in the condensed phase. Several radical cation transformations observec are only photochemically allowed, that is, involvement of higher electronic states of radical cations is indicated. The fact that all the transformations in zeolites are thermally allowed means that some zeolite matrix sites can stabilize higher electronic states of ions.

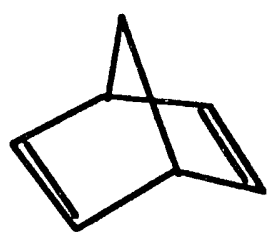

\section{NBD}

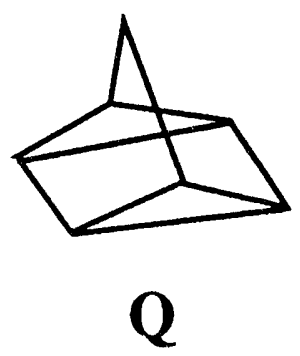

The results of this study, executed by Drs. A. D. Trifunac and M. V. Barnabas of the Chemistry Division of Argonne National Laboratory, are significant because (a) $\mathrm{C}_{7} \mathrm{H}_{8}$ compounds are excellent candidates for chemical energy storage; and (b) zeolites can be used to control chemistry via the matrix substrate interaction and thus significantly lower the potential energy barrier for carbon framework transformations. This opens a venue for more sophisticated use of zeolite catalysts, going beyond the size-restriction effects.

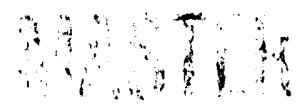




\title{
PHOTOCHEMISTRY WITHOUT PHOTONS. RADICAL CATION CHEMISTRY IN ZEOLITES
}

\author{
A. D. Trifunac and M. V. Barnabas \\ Chemistry Division, Argonne National Laboratory
}

The interconversion of the $\mathrm{C}_{7} \mathrm{H}_{8}$ molecular framework, especially norbornadiene (NBD) and quadricyclane (Q), has been considered for photochemical energy storage. Actually, very little was known about the details of these carbon-skeleton transformations, and only one radical cation species (NBD $\left.{ }^{+}\right)$was characterized.

We have undertaken a thorough study of these systems using zeolite matrices. We have shown that zeolites have exceptional properties, allowing unprecedented control of chemical reactivity.

The radical cation chemistry of $\mathrm{NBD}^{+}$and $\mathrm{Q}^{+}$in zeolites is remarkable. We have been able to observe a great many radical cations and radicals. Previous studies in the gas phase have suggested and observed some such processes, although there was no precedent for such chemistry in the condensed phase.

In the attached scheme, we outline some of the species we were able to characterize. The crucial aspect of the zeolite matrix is that one can tune the matrix-radical cation interaction by varying the matrix polarity. The ZSM-5 zeolites of identical structure with different Si/Al ratio are ideally suited for such study.

Without discussing all the transformations, we should point out that several processes, such as the reverse Diels-Alder reaction

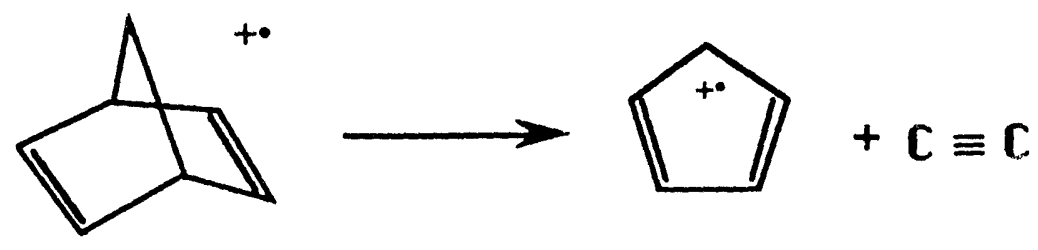


are known to occur by invurement of highly excited states. They were seen previously in the gas phase in electron-impact and pyrolysis studies. That we ar', able to carry out such reactions in zeolites means that sites in the zeolite matrix are able to stabilize high electronic states of ions, significantly lowering the potential energy barrier for such reactions. Thus, we are able to thermally drive otherwise photodriven reactions. This is remarkable, and it provides further insight into the catalytic possibilities using zeolites and related silica materials. It also clearly illustrates that such channel materials do not act by size effects alone, it is the matrix-substrate ion interaction that allows some otherwise forbidden process to be thermally driven in the condensed phase.

These studies also suggest that many ideas and mechanisms of transformations and reactions in this fascinating system can all be explained by considering radical ion chemistry alone. There is no need to invoke exotic neutral excited states or diradicals as some have done in the past.

\section{DISCLAIMER}

\footnotetext{
This report was prepared as an account of work sporisored by an agency of the United States Government. Neither the United States Government nor any agency thereof, nor any of their employees, makes any warranty, express or implied, or assumes any legal liability or responsibility for the accuracy, completeness, or usefulness of any information, apparatus, product, or process disclosed, or represents that its use would not infringe privately owned rights. Reference herein to any specific commercial produst, process, or service by trade name, trademark, manufacturer, or otherwise does not necessarily constitute or imply its endorsement, recommendation, or favoring by the United States Government or any agency thereof. The views and opinions of authors expressed herein do not necessarily state or reflect those of the United States Government or any agency thereof.
} 


\section{Radical cation Chemistry of Ouadricyclane and Norbornadiene}
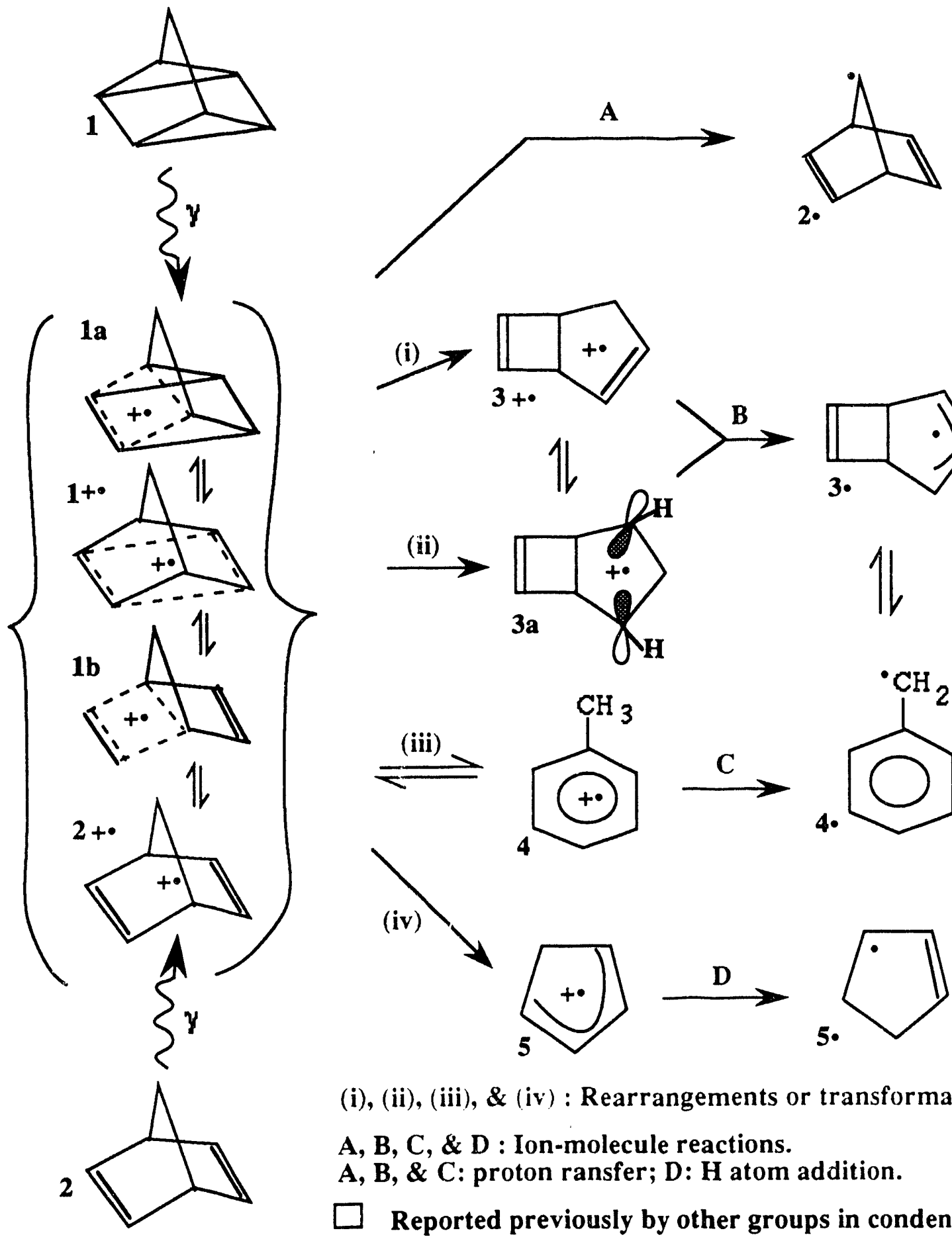

(i)
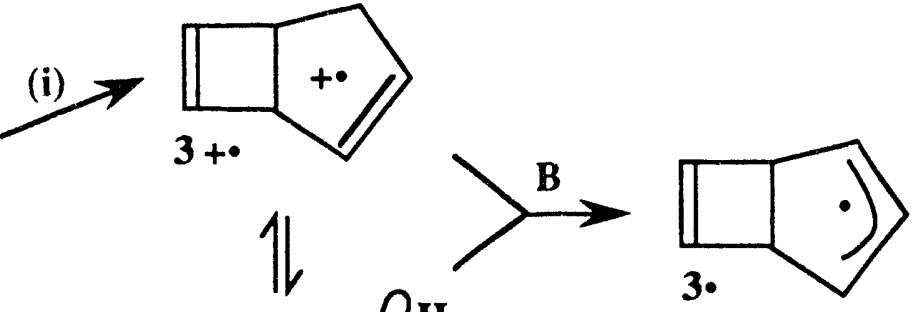

(ii)<smiles>O[C@H]1C[C@H](O)[C@H]2C=C[C@H]12</smiles><smiles>C#CC=C</smiles>

(iii)

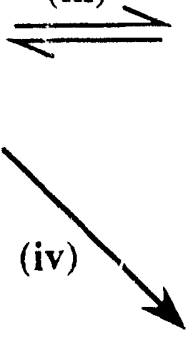<smiles>Cc1ccccc1</smiles><smiles>CCCC</smiles><smiles>[CH2]c1ccccc1</smiles>

(i), (ii), (iii), \& (iv) : Rearrangements or transformations.

A, B, C, \& D : Ion-molecule reactions.

$A, B, \&$ C: proton ransfer; D: $\mathbf{H}$ atom addition.

Reported previously by other groups in condensed phase.

Observed in zeolites in addition to the species reported before. 

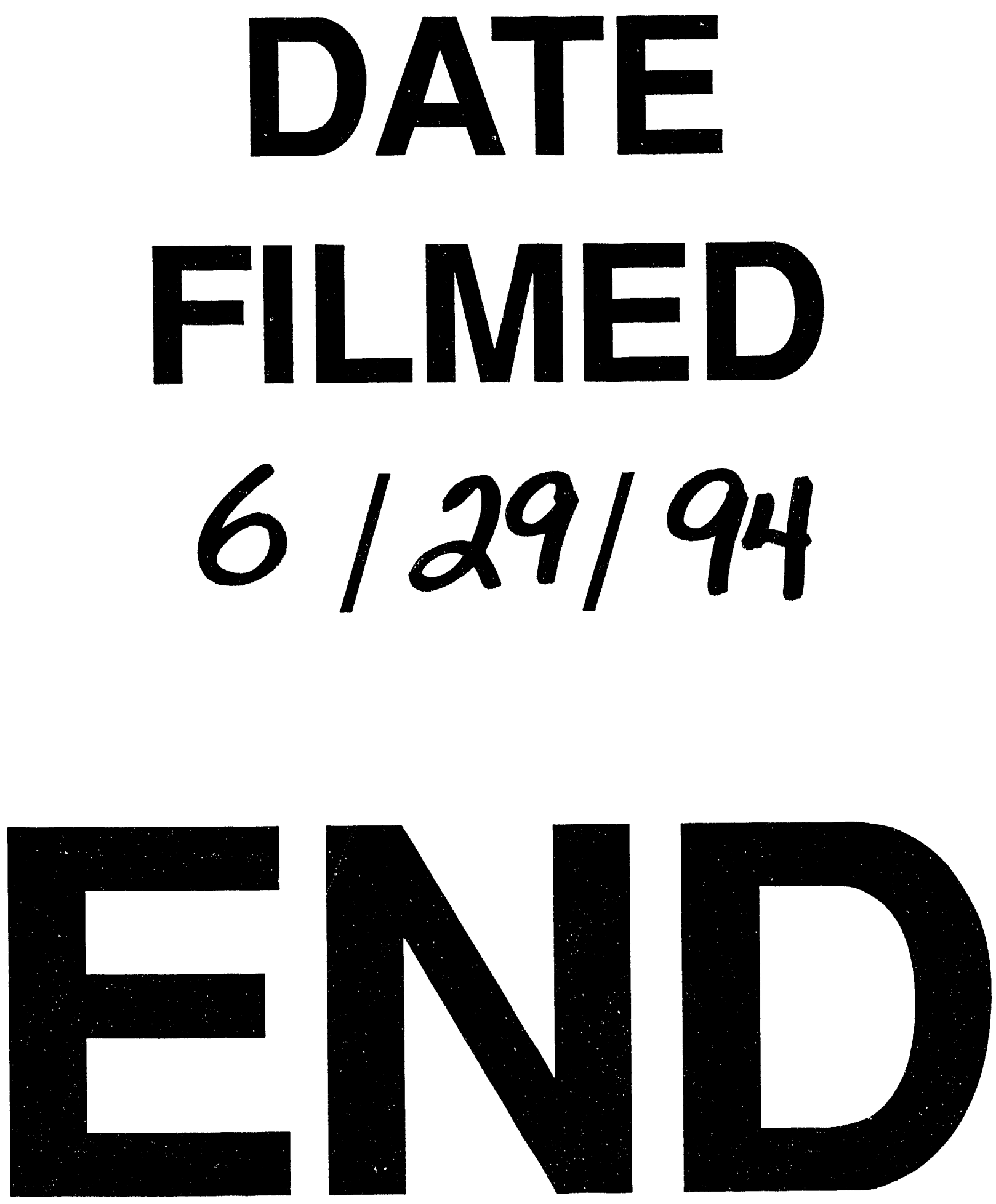
. . . - . 